Article

\title{
Discrimination of Switchgrass Cultivars and Nitrogen Treatments Using Pigment Profiles and Hyperspectral Leaf Reflectance Data
}

\author{
Anserd J. Foster ${ }^{1}$, Vijaya Gopal Kakani ${ }^{1, *}$, Jianjun Ge $^{2}$ and Jagadeesh Mosali ${ }^{3}$ \\ 1 Department of Plant and Soil Sciences, Oklahoma State University, Stillwater, OK 74078, USA; \\ E-Mail: anserd@ostatemail.okstate.edu \\ 2 Department of Geography, Oklahoma State University, Stillwater, OK 74078, USA; \\ E-Mail: jianjun.ge@okstate.edu \\ 3 The Samuel Roberts Noble Foundation, Inc., 2510 Sam Noble Parkway, Ardmore, OK 73401, USA; \\ E-Mail: jmosali@noble.org \\ * Author to whom correspondence should be addressed; E-Mail: v.g.kakani@okstate.edu; \\ Tel.: +1-405-744-4046; Fax: +1-405-744-5269.
}

Received: 18 July 2012; in revised form: 16 August 2012 / Accepted: 28 August 2012 /

Published: 10 September 2012

\begin{abstract}
The objective of this study was to compare the use of hyperspectral narrowbands, hyperspectral narrowband indices and pigment measurements collected from switchgrass leaf as potential tools for discriminating among twelve switchgrass cultivars and five $\mathrm{N}$ treatments in one cultivar (Alamo). Hyperspectral reflectance, UV-B absorbing compounds, photosynthetic pigments (chlorophyll a, chlorophyll $\mathrm{b}$ and carotenoids) of the uppermost fully expanded leaves were determined at monthly intervals from May to September. Leaf hyperspectral data was collected using ASD FieldSpec FR spectroradiometer (350-2,500 nm). Discrimination of the cultivars and $\mathrm{N}$ treatments were determined based on Principal Component Analysis (PCA) and linear discriminant analysis (DA). The stepwise discriminant analysis was used to determine the best indices that differentiate switchgrass cultivars and nitrogen treatments. Results of PCA showed $62 \%$ of the variability could be explained in PC1 dominated by middle infrared wavebands, over 20\% in PC2 dominated by near infrared wavebands and just over 10\% in PC3 dominated by green wavebands for separating both cultivars and $\mathrm{N}$ treatments. Discriminating among the cultivars resulted in an overall accuracy of $81 \%$ with the first five PCs in the month of September, but was less accurate $(27 \%)$ in classifying $N$ treatments using the spectral data. Discrimination based on pigment data using the first two PCs resulted in an overall accuracy of less than $10 \%$ for separating
\end{abstract}


switchgrass cultivars, but was more accurate (47\%) in grouping $\mathrm{N}$ treatments. The plant senescence ratio index (PSRI) was found to be the best index for separating the cultivars late in the season, while the transform chlorophyll absorption ratio index (TCARI) was best for separating the $\mathrm{N}$ treatments. Leaf spectra data was found to be more useful than pigment data for the discrimination of switchgrass cultivars, particularly late in the growing season.

Keywords: hyperspectral; pigments; reflectance; vegetation indices; switchgrass

\section{Introduction}

Switchgrass (Panicum virgatum L.), a native North American warm-season C4 perennial grass has been identified as a potential biofuel feedstock with a promise for production across diverse climates in North America [1-3]. Switchgrass is adapted to a wide range of climatic and edaphic conditions from northern Mexico to southern Canada, and from the Atlantic coast to the Rocky Mountains [3]. It is classified as a dedicated biofuel feedstock due to its high level of productivity over long-term (>10 yr) across varied environmental conditions [4], suitability for production on marginal land [3], low nutrient requirements [1,5], and positive environmental benefits such as reduced erosion, increased water quality, enhanced soil-carbon sequestration, wildlife habitat and reducing greenhouse gas emissions [2].

Two major types of switchgrass are found in North America: the low land ecotype is exclusively tetraploid, associated with wet conditions and better adapted to lower latitudes, while the upland ecotype is mainly tetraploid or octaploid, associated with dry conditions and better adapted for mid to northern latitudes [6,7]. Because of these distinct differences between and within the upland and lowland ecotypes, it is important to be able to discriminate switchgrass plants. Current methods of identification of specific cultivars are limited to genomic analysis and visual discrimination. Despite genomics analysis only requiring a small amount of sample material, expensive equipment and expertise are needed to make the assessment. While, visual discrimination is possible with trained personnel, results among personnel and locations can vary due to plants of different age and localized effect of light, temperature and moisture.

Remote sensing is a well-known non-destructive method that can play a critical role as a crop stress assessment tool, monitoring nutrient status, disease and weed and insect infestation. The basic concept of remote sensing is the ability to quantify variations due to space and size (spatial variations), variations in reflected or emitted radiation (spectral variations) and variations of reflected or emitted radiation, space and size over time (temporal variations) [8]. Radiation reflected by vegetation varies in different part of the spectrum due to the vegetation biophysical characteristics. In the visible part of the spectrum (400-700 nm) the amount of reflected or emitted radiation is controlled by the plant pigmentation the chlorophyll, carotenes and xanthophylls [8]. In the near infrared portion of the spectrum $(700-1,350 \mathrm{~nm})$ reflected or emitted radiation is controlled by the internal leaf structures. The middle infrared (Mid-IR) portion of the spectrum (1,350-2,500 $\mathrm{nm}$ ) reflected or emitted radiation is controlled primarily by in vivo water content and secondarily by internal leaf structures [8]. The importance of these parts of the spectrum (Mid-IR) is the high resolution spectral response that is often 
observed for a crop at leaf or canopy level at different stages of development. As a plant develops and interacts with environmental conditions, reflectance from these areas of the spectrum is affected. Reflectance tends to increase in the near-infrared (NIR; 725-900 nm) as the internal leaf structure of most plant species (i.e., cotton canopy) reflects more of the energy in this portion, and changes in green peak $(550 \mathrm{~nm})$ and in red region $(650-690 \mathrm{~nm})$ due to chlorophyll reflectance and adsorption respectively [9].

The recent advances in ground-based high resolution multispectral, hyperspectral digital cameras, spectroradiometers and several other optical sensors can play a critical role towards a more intelligent crop production system. Narrowbands located in specific portions of the spectrum have been shown to significantly improve discrimination capabilities and classification accuracies for various vegetation and agricultural crops when compared to broadbands such as Landsat Thematic Mapper TM and Systeme Pour L'Observation de la Terre (SPOT) [10]. Hyperspectral narrowbands and vegetative indices developed from them are capable of detecting small differences in percentage green cover [11], crop moisture variations [12] and discriminating among varieties [13,14]. Despite, the improvement of narrowbands over broadband, the large number of bands available with hyperspectral sensors makes analysis complex and time consuming [14]. Several approaches were used including reflectance from individual narrowbands, various ratios and indices, and multivariate statistical analysis to discriminate among varieties. The use of high resolution hyperspectral leaf reflectance with pigment profiles to discriminate among sugarcane varieties was investigated [13]. The hyperspectral reflectance data was collected at $350-800 \mathrm{~nm}$ at $0.4 \mathrm{~nm}$ intervals from the third youngest fully open leaf and plant pigment analysis was done from the same leaf. The authors reported that several single wavelengths ranging from 560 to $720 \mathrm{~nm}$ were able to discriminate between selected varieties, multivariate analysis resulted in a $95-100 \%$ correct classification for all varieties with leaf reflectance data in comparison to $76-81 \%$ correct classification with plant pigment data and $81-86 \%$ using vegetative indices [NDVI (Normalize Difference Vegetative Index) and WDRVI (Wide Dynamic Range Vegetative Index)]. Hyperspectral narrowband wavelengths from 375 to $1,075 \mathrm{~nm}$ and multiple discriminant analysis were used by Ray et al. [14] to identify nine bands (520, 560, 660, 690, 730, 760, 780,790 and $800 \mathrm{~nm})$ and vegetative indices, simple ratio, ZTM (Zarco Tejada and Miller), Red edge 750/700 and Red edge 740/720 for discriminating among four potato varieties. Likewise, Hatfield and Prueger [15] used different vegetative indices to quantify differences among varieties of corn and soybean at different growth stages during the growing season. The authors concluded that the ability to quantify differences among the varieties and crops was a function of growth stage and vegetative index.

The use of hyperspectral remote sensing techniques, with high spectral resolutions, in combination with plant pigment analysis may significantly improve the ability to discriminate between and among switchgrass cultivars and ecotypes. The dominant plant pigments are the chlorophylls. These compounds exhibit pronounced absorption in the bluish $(400-500 \mathrm{~nm})$ and reddish $(600-700 \mathrm{~nm})$ wavelengths of the magnetic spectrum. Other plant pigments such as carotenoids produces yellow or orange reflectance centered at about $450 \mathrm{~nm}$ wavelength of the spectrum. Knowledge of pigment pools including those associated with UV-B absorption could improve our understanding of plant stress responses to light, temperature and water, and could also be used to discriminate between species, cultivars and varieties of switchgrass. The objective of this study was to compare the use of hyperspectral narrowbands, hyperspectral narrowband vegetation indices and leaf pigmentation 
(Chlorophyll a, Chlorophyll b, Carotenoids) to discriminate between 12 switchgrass cultivars and five nitrogen treatments for one of the cultivars (Alamo) at different times during the growing season.

\section{Materials and Methods}

\subsection{Experimental Design}

\subsubsection{Switchgrass Cultivars}

An experiment consisting of twelve cultivars of switchgrass (Figure 1) with known difference in ecotype, and origin (Table 1) was established at the Stillwater Agronomy Research Station $\left(36.12^{\circ} \mathrm{N}\right.$, $97.09^{\circ} \mathrm{W}$ ) in April 2009 to evaluate biomass yield production among the cultivars. Switchgrass cultivars were planted by seed in plots $(6.10 \mathrm{~m}$ wide $\times 7.62 \mathrm{~m}$ long $)$ in a randomized complete block design with three replications. Plots were seeded at a rate of $5.04 \mathrm{~kg} \cdot \mathrm{ha}^{-1}$ of pure live seed using a no-till planter. Leaf samples were collected on 24 May, 20 June, 25 July, 24 August and 30 September 2011 from which the spectral and pigment data was obtained (Table 2).

Figure 1. Twelve switchgrass cultivars grown in Stillwater Oklahoma (OK) for Biomass yield potential, (A) Carthage; (B) Alamo; (C) Kanlow; (D) Southlow; (E) Cave-In-Rock; (F) Forestburg; (G) Blackwell; (H) Nebraska 28; (I) Shelter; (J) Shawnee; (K) Sunburst; (L) Cimarron.

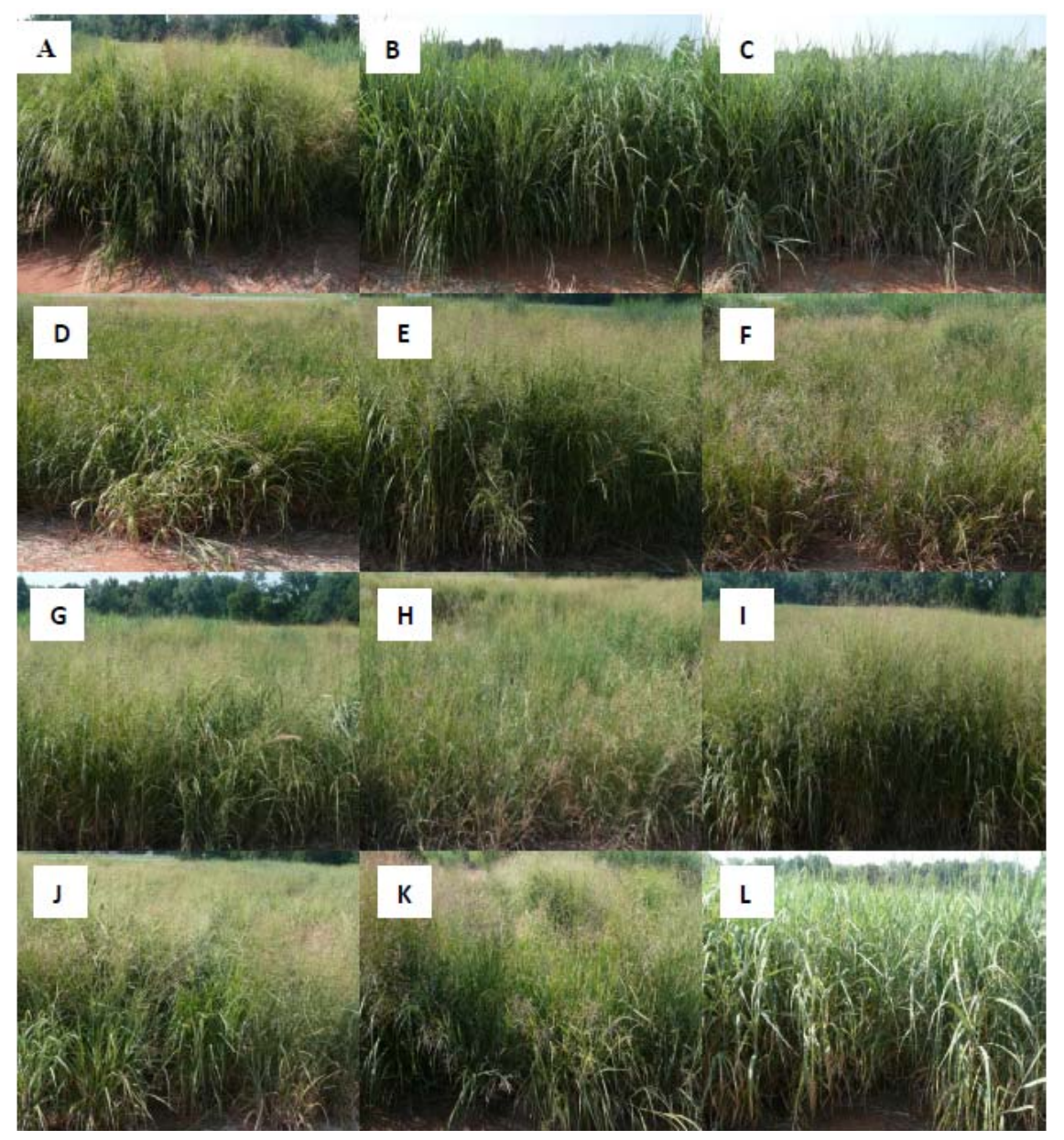


Table 1. Twelve switchgrass cultivars grown in OK for biomass yield potential and their ecotype designation and origin.

\begin{tabular}{lcl}
\hline Cultivars & Ecotype & Origin \\
\hline Cimmaron & Lowland & Oklahoma \\
Alamo & Lowland & South central Texas \\
Kanlow & Lowland & East central Oklahoma \\
Blackwell & Upland & North east Oklahoma \\
Carthage & Upland & Carthage, North Carolina \\
Cave-In-Rock & Upland & Southern Illinois \\
Forestburg & Upland & East central South Dakota \\
Nebraska 28 & Upland & North east Nebraska \\
Shelter & Upland & North west, West Virginia \\
Sunburst & Upland & Southeastern South Dakota \\
Shawnee & Upland & Shawnee National Forest, Illinois \\
Southlow & Upland & Michigan \\
\hline
\end{tabular}

\subsubsection{Nitrogen Treatments}

An experiment consisting of five nitrogen treatments (winter legume (hairy vetch), 0, 84, 168 and $252 \mathrm{~kg} \cdot \mathrm{N} \cdot \mathrm{ha}^{-1}$ ) was established at the Stillwater Agronomy Research Station (EFAW Site, $36.13^{\circ} \mathrm{N}$, $97.10^{\circ} \mathrm{W}$ ) in a one year old established stand of switchgrass "Alamo" to evaluate the effect of nitrogen treatment on biomass production. Experimental design is a randomized complete block and replicated three times. No nitrogen fertilizer was applied in the establishment year. Plots were fertilized with the different rates of $\mathrm{N}$ on 3 June 2011. Leaf samples were collected on 17 June, 27 July and 27 August 2011 from which the spectral and pigment data was obtained (Table 2).

Table 2. Summary of sampling intervals and total number of samples per spectral and pigment measurements. Nine spectral samples were taken at each interval for each cultivar and nitrogen treatment. Three pigment measurements were taken for each cultivar and nitrogen treatment per sampling interval.

\begin{tabular}{ccc}
\hline Sampling Dates & \# of Spectral Samples & \# of Pigment Samples \\
\hline & Switchgrass Cultivars & \\
24 May & 108 & 36 \\
20 June & 108 & 36 \\
25 July & 108 & 36 \\
24 August & 108 & 36 \\
30 September & 108 & 36 \\
& Nitrogen Treatments & \\
17 June & 45 & 15 \\
27 July & 45 & 15 \\
27 August & 45 & 15 \\
\hline
\end{tabular}




\subsection{Leaf Sampling}

Top most fully expanded leaf (6th or 5th) was excised from 6 random plants in each plot and sealed in a plastic bag in an ice chest and transported to the laboratory for spectral and pigment measurements. These samples were collected between 10:00 and 15:00 $\mathrm{h}$ local time.

\subsection{Spectral Data}

Hyperspectral reflectance data was collected using an ASD Field Spec Pro spectroradiometer (Analytical Spectral Devices Inc., Boulder, CO, USA) that consisted of a spectral range of 350-2,500 nm and a $25^{\circ}$ field of view. The spectrometer is equipped with three sensors [(visible $(400-750 \mathrm{~nm})$ and near infrared-NIR (750-1,100 nm), shortwave infrared-SWIR1 (1,000-1,800 nm) and SWIR2 $(1,800-2,500 \mathrm{~nm})]$ with spectral sampling of 3,10 and $10 \mathrm{~nm}$, respectively. The instrument was periodically calibrated using a standard Spectralon white reference panel (Labsphere Inc., North Sutton, NH, USA). The white reference was measured at $15 \mathrm{~min}$ intervals to check the instrument stability for $100 \%$ reflectance. To measure leaf reflectance, two leaves were place beside each other to provide a large enough surface area, and sandwiched between the non-reflecting, black body and the light probe. This ensured that no extraneous light entered the sensor during these measurements. Care was taken in placing the leaves beside each other, to ensure that no space or overlapping occurred. Three replicated measurements were made on leaves collected from each plot. Built-in spectral resolution output of the data from the ASD operating system is $1 \mathrm{~nm}$ along the whole spectrum. To reduce the amount of data for analysis, spectral data were averaged at 10 -nm wavelength intervals (e.g., a band center at 400 was the averaged value between $395-405 \mathrm{~nm}$ ) giving a total of 211 spectral bands between 400-2,500 nm. Spectral data at start of spectrum due to noise (350-395 nm) and in the atmospheric water absorption spectral regions (1,350-1,420 and 1,800-1,960 nm) were deleted from the data before analysis leaving 186 spectral bands for analysis.

\subsection{Pigment Analysis}

After reflectance measurements, five of the leaves used for hyperspectral measurements were sampled for plant pigment analysis. The photosynthetic pigments (Chlorophyll a, Chlorophyll b and Carotenoids) were extracted by placing five $38.5 \mathrm{~mm}^{2}$ leaf discs in a vial with $5 \mathrm{~mL}$ of dimethyl sulfoxide and extracting after incubating in a dark room for $24 \mathrm{~h}$. The absorption of the extracts was determined at 664, 648 and $470 \mathrm{~nm}$ using the spectrophotometer. The equations by Lichtenthaler [16] were used to derive the pigment concentrations.

The UV-B absorbing compounds were determined using methods described in Kakani et al. [17]. UV-B absorbing compounds were extracted from placing five $38.5 \mathrm{~mm}^{2}$ leaf discs in a vial with $10 \mathrm{~mL}$ of aliquot consisting of a methanol, water and hydrochloric acid in the proportion of 79:20:1 ratio. The vials were incubated at room temperature for $24 \mathrm{~h}$ in dark to allow for complete extraction of UV-B absorbing compounds. The absorbance of the extracts from the different cultivars was measured at $330 \mathrm{~nm}$. The content of UV-B absorbing compounds was calculated using the equation [17], $\mathrm{C}=16.05 \times \mathrm{A}$, where $\mathrm{A}$ is absorbance at $330 \mathrm{~nm}$ and $\mathrm{C}$ is concentration of $\mathrm{UV}-\mathrm{B}$ absorbing compound $\left(\mu \mathrm{g} \cdot \mathrm{mL}^{-1}\right.$ of extract). 


\subsection{Data Analysis}

The optimal wavebands that were able to discriminate the target as affected by time of collection were determined based on a comprehensive analysis using principal component analysis (PCA). The goal of the PCA is to identify underlying variables, or factors that explain the pattern of correlations within a set of observed variables. The PCA tends to achieve this by deriving a new set of uncorrelated variables called principal components, thereby reducing the number of variables. The PCA was carried out using the PRINCOMP procedure in SAS [18].

To evaluate the effect of time of collection in differentiating among the cultivars and $\mathrm{N}$ treatments a linear discriminant analysis with cross validation was done for each month. Discriminant function analysis (DA) is a qualitative tool often used to discriminate between two or more groups. To classify observations into a group, a mathematical rule or discriminant function is used to determine to which group an observation belongs based on knowledge of the quantitative variables only. In this study, DA was used to classify the twelve cultivars and five $\mathrm{N}$ treatments, by computing a sample's distance from each class center in Mahalanobis distance (MD) units [19]. The MD is the parameter that is calculated and used to determine how close to the center of its group is an individual spectrum sample. The MD was calculated using the following equation [19]:

$$
D_{i j}^{2}=\left[A v\left(x_{i}\right)-A v\left(x_{j}\right)\right]^{\prime} \operatorname{cov}^{-1}\left[A v\left(x_{i}\right)-A v\left(x_{j}\right)\right]
$$

where $D_{i j}^{2}$ denotes the MD between the cultivars $i$ and $j, \operatorname{cov}^{-1}$ denotes the inverse covariance matrix, and $A v\left(x_{i}\right)$ and $A v\left(x_{i}\right)$ denote the mean reflection for cultivars $i$ and $j$, respectively. The smallest MD is used to pick the group that the individual fits best. The equation assumes a common variance for the populations from which the groups are derived. Discriminant function analysis was carried out on the first five PCAs resulting from the PCA as they covered most of the variation $(99 \%$ of variation explained) contained in the raw spectral data.

Selected hyperspectral narrowband vegetation indices that take into account leaf structure, pigmentation and red edge characteristics were computed for each set of spectral data. The vegetation indices computed are shown in Table 3. Stepwise discriminant analysis (SDA) was carried out to find the best indices which can differentiate switchgrass cultivars and nitrogen treatments at each sampling interval. The SDA is a procedure that reduces the data set to those variables that maximize between statistical group variability while minimizing within group variability. The difference between PCA and SDA is that the PCA creates a new set of uncorrelated variables that defines the axes of greatest variability in the data, while SDA identifies from among the original variables, the best variables that describes differences between given groups. The Wilk's lambda statistics was used to select the best vegetation indices for differentiating the cultivars and $\mathrm{N}$ treatments. Low Wilk's Lambda valve suggests a great degree of separation. Therefore, index with the lowest Wilk's lambda value resulted in the greatest separation among the cultivars and $\mathrm{N}$ treatments.

Similarly, PCA and DA were performed at each sampling date for the pigment content to determine degree of discrimination. Discriminant analysis was carried out on the two first PCAs as they contain most of the variation ( $99 \%$ of variation explained). The results were compared to determine the approach and the sampling interval that provided the greatest separation. All statistical analyses were performed using SAS (Statistical Analysis System) [18]. 
Table 3. Narrowband hyperspectral vegetation indices used in the study.

\begin{tabular}{|c|c|c|}
\hline Index & Wavebands & References \\
\hline \multicolumn{3}{|l|}{ Structural Indices } \\
\hline Simple Ratio (SR) & $\mathrm{SR}=\mathrm{R}_{\mathrm{NIR}} / \mathrm{R}_{\mathrm{red}}$ & [20] \\
\hline & Red NDVI $=\left(\mathrm{R}_{\mathrm{NIR}}-\mathrm{R}_{\mathrm{red}}\right) /\left(\mathrm{R}_{\mathrm{NIR}}+\mathrm{R}_{\mathrm{red}}\right)$ & {$[21]$} \\
\hline Normalized Diffarence Veoratation Index (NDVD) & Green NDVI $\left(\mathrm{R}_{\mathrm{NIR}}-\mathrm{R}_{\text {green }}\right) /\left(\mathrm{R}_{\mathrm{NIR}}+\mathrm{R}_{\text {green }}\right)$ & [22] \\
\hline 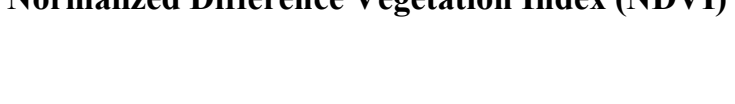 & Red Edge NDVI $=\underset{\text { edge }}{\left(\mathrm{R}_{\text {NIR }}-\mathrm{R}_{\text {red edge }}\right) /\left(\mathrm{R}_{\mathrm{NIR}}+\mathrm{R}_{\mathrm{red}}\right.}$ & {$[22]$} \\
\hline $\begin{array}{l}\text { Renormalized Difference Vegetation Index } \\
\text { (RDVI) }\end{array}$ & $\mathrm{RDVI}=\left(\mathrm{R}_{800}-\mathrm{R}_{670}\right) /\left(\mathrm{R}_{800}+\mathrm{R}_{670}\right)^{0.5}$ & [23] \\
\hline Enhanced Vegetation Index (EVI) & $\mathrm{EVI}=2.5\left(\mathrm{R}_{\mathrm{NIR}}-\mathrm{R}_{\text {red }}\right) /\left(\mathrm{R}_{\mathrm{NIR}}+6 \mathrm{R}_{\text {red }}-7.5 \mathrm{R}_{\text {blue }}+1\right)$ & [24] \\
\hline Plant Senescence Reflectance Index (PSRI) & $\mathrm{PSRI}=\left(\mathrm{R}_{660}-\mathrm{R}_{510}\right) / \mathrm{R}_{760}$ & {$[15,25]$} \\
\hline \multicolumn{3}{|l|}{ Chlorophyll/Pigment Related Indices } \\
\hline & $\mathrm{Cl}_{\text {green }}=\left(\mathrm{R}_{\mathrm{NIR}} / \mathrm{R}_{\text {green }}\right)-1$ & {$[22,26]$} \\
\hline Cnlorophyil Indices & $\mathrm{Cl}_{\text {red edge }}=\left(\mathrm{R}_{\mathrm{NIR}} / \mathrm{R}_{\text {red edge }}\right)-1$ & {$[22,26]$} \\
\hline $\begin{array}{l}\text { Normalized Pigment Chlorophyll Ratio Index } \\
\text { (NPCI) }\end{array}$ & $\mathrm{NPCI}=\left(\mathrm{R}_{660}-\mathrm{R}_{460}\right) /\left(\mathrm{R}_{660}+\mathrm{R}_{460}\right)$ & {$[25]$} \\
\hline Modified CARI (MCARI) & $\begin{array}{c}\operatorname{MCARI}=\left[\left(\mathrm{R}_{700}-\mathrm{R}_{670}\right)-0.2\left(\mathrm{R}_{700}-\mathrm{R}_{500}\right)\right. \\
\left.\left(\mathrm{R}_{700} / \mathrm{R}_{670}\right)\right]\end{array}$ & [27] \\
\hline Transformed CARI (TCARI) & $\begin{array}{c}\text { TCARI }=3\left[\left(\mathrm{R}_{700}-\mathrm{R}_{670}\right)-0.2\left(\mathrm{R}_{700}-\mathrm{R}_{500}\right)\right. \\
\left.\left(\mathrm{R}_{700} / \mathrm{R}_{670}\right)\right]\end{array}$ & [28] \\
\hline Triangular Vegetation Index (TVI) & $\mathrm{TVI}=0.5\left[120\left(\mathrm{R}_{750}-\mathrm{R}_{550}\right)-200\left(\mathrm{R}_{670}-\mathrm{R}_{550}\right)\right.$ & [29] \\
\hline Structural Insensitive Pigment Index (SIPI) & $\mathrm{SIPI}=\left(\mathrm{R}_{800}-\mathrm{R}_{430}\right) /\left(\mathrm{R}_{800}+\mathrm{R}_{680}\right)$ & {$[30]$} \\
\hline \multicolumn{3}{|l|}{ Red Edge Indices } \\
\hline Red edge (750-700) & $\mathrm{R}_{750}-\mathrm{R}_{700}$ & [31] \\
\hline Red edge (740-720) & $\mathrm{R}_{740}-\mathrm{R}_{720}$ & [32] \\
\hline Zarco Tejada and Miller (ZTM) & $\mathrm{ZTM}=\left(\mathrm{R}_{750} / \mathrm{R}_{710}\right)$ & [33] \\
\hline
\end{tabular}

\section{Results}

\subsection{Principal Component Analysis}

It is evident from Figure 1 that there was a difference in reflectance at the different sampling dates and among the cultivars. Clear varietal and sampling interval differences were visible in reflectance in almost all the regions of the spectrum. The most distinct differences among the cultivars were observed for the June and September sampling date in the visible, near infrared and early short-wave infrared regions of the spectrum (Figure 2). Small differences in reflectance were also observed in the different regions of the spectrum for the nitrogen treatments (Figure 3). Similar to the cultivars, the most distinct differences were observed in the visible, near infrared and early short-wave infrared regions of the spectrum. In general, reflectance showed an increasing trend with time throughout the growing season. However, to quantify the wavebands having the greatest influence on separating the cultivars and nitrogen treatments at the different sampling dates, principal component analysis was used to reduce the 186 wavebands hyperspectral data to a few bands that explain most of the variability. The first three principal components (Eigen values greater than 1) explained 93-97\% of the variability for the five collection months. Therefore, to explain more than $90 \%$ of the variability, the 
186 wavebands can be reduced to two to three new principal components wavebands (PC1 to PC3). Table 4 provides the five wavebands with the highest factor loading for each principal components resulting in 15 bands in three different regions of the spectrum. The order in which the bands are listed in Table 4 indicates the magnitude or ranking for that band based on its factor loadings. Therefore, for PC1 waveband centered at 1,670 has the highest factor loading followed by 1,660, 1,680, 1,690 and $1,700 \mathrm{~nm}$.

Figure 2. Mean leaf spectral profile of twelve switchgrass collected in May, June, July, August and September of 2011. (Top left) figure shows leaf spectral profile for the month of May; (Top right) figure for the month of June; (Middle left) figure shows for the month of July; (Middle right) figure shows for month of August, and (Bottom left) figure shows the month of September. Nine spectral measurements were taken per cultivar at each sampling interval.
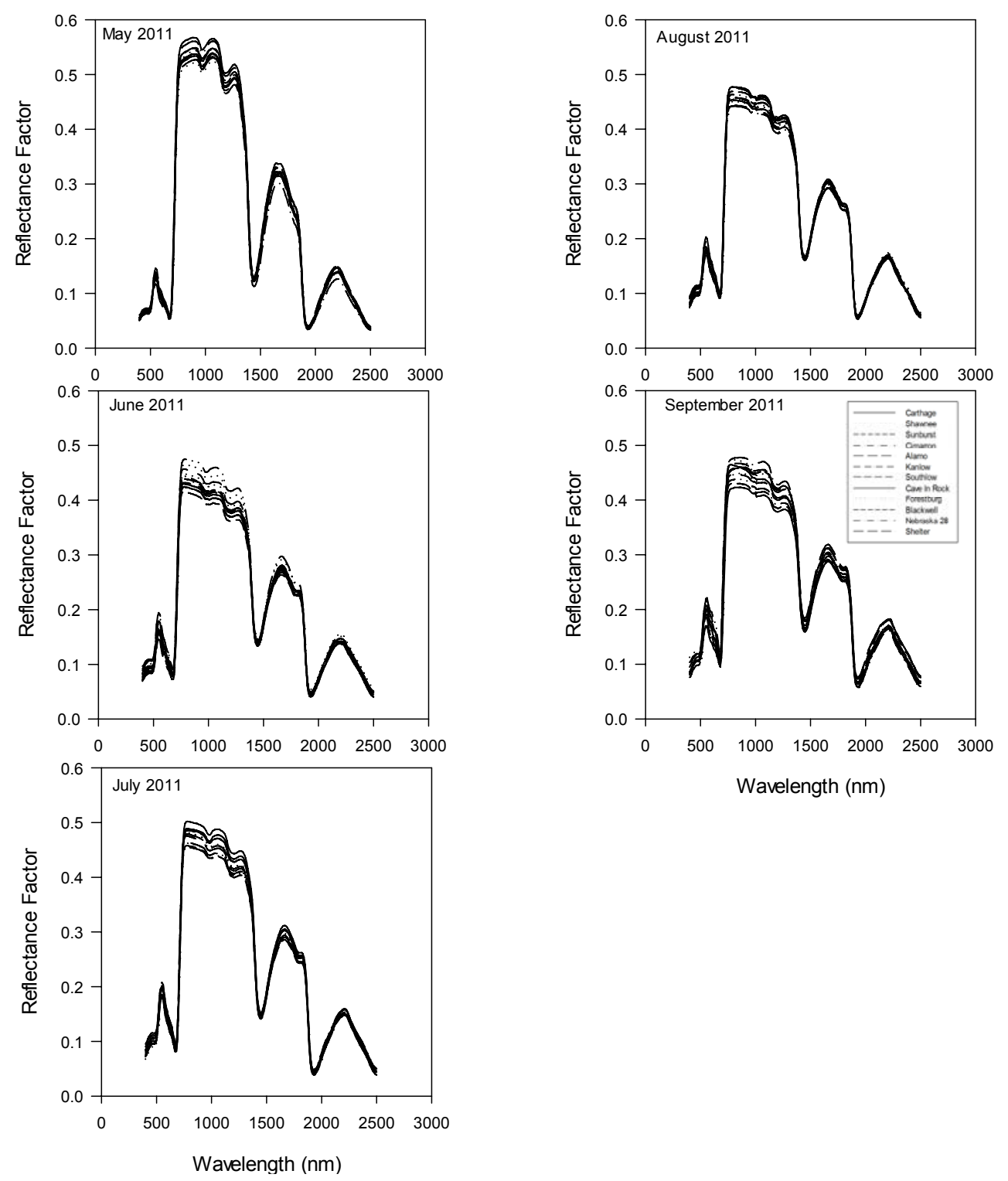
Figure 3. Mean leaf spectral profile for five nitrogen treatments collected in June, July and August of 2011. (Top) figure shows leaf spectral profile for the month of June; (Center) figure shows for month of July, and (Bottom) figure shows for the month of August. N1-0: $0 \mathrm{~kg} \cdot \mathrm{N} \cdot \mathrm{ha}^{-1}, \mathrm{~N} 2-84: 84 \mathrm{~kg} \cdot \mathrm{N} \cdot \mathrm{ha}^{-1}, \mathrm{~N} 3-168: 168 \mathrm{~kg} \cdot \mathrm{N} \cdot \mathrm{ha}^{-1}, \mathrm{~N} 4-252: 252 \mathrm{~kg} \cdot \mathrm{N} \cdot \mathrm{ha}^{-1}$, and N5-WL: Winter legume (hairy Vetch). Nine spectral measurements were taken per $\mathrm{N}$ treatment at each sampling interval.
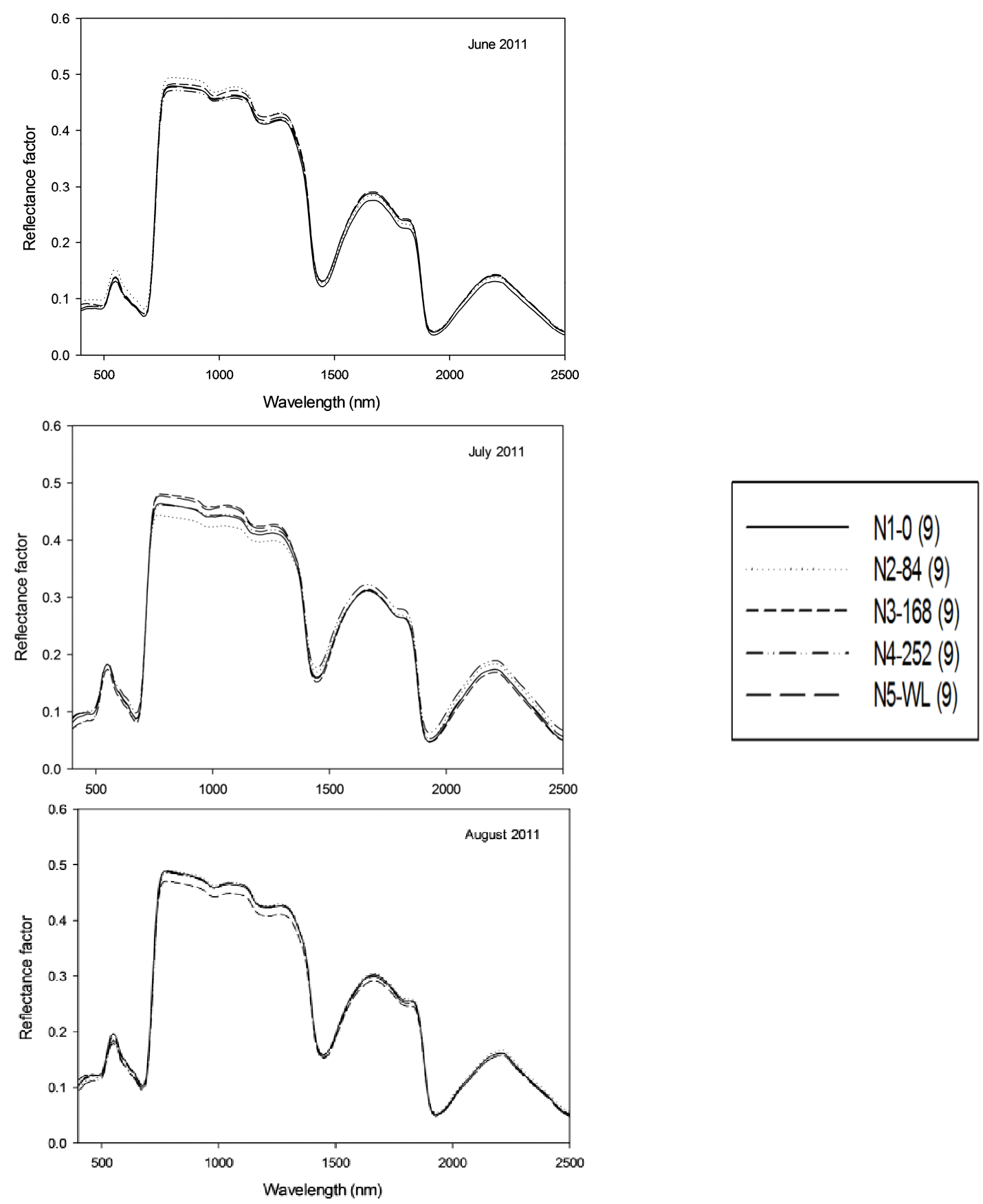

The PC1 was dominated by the middle infrared (Mid-IR) bands explaining $63 \%$ of the variability, PC2 by middle infrared (Mid-IR) bands explaining 22\% of the variability, and PC3 by the red region of the spectrum explaining $11 \%$ of the variability for the switchgrass cultivars. Similarly, PC1 for nitrogen treatments was dominated by Mid-IR bands explaining 53\% of the variability, PC2 by NIR 
bands explaining $29 \%$ of the variability (Table 4). However, PC3 was dominated by green bands explaining $14 \%$ of the variability.

Table 4. Shows PCA results with five wavebands with the highest factor loadings (Eigen vectors) and the percent variability explained by each principal component for characterizing 12 switchgrass cultivars and five nitrogen treatments.

\begin{tabular}{|c|c|c|c|c|c|c|c|}
\hline & \multicolumn{3}{|c|}{$\begin{array}{c}\text { Wavelength Centered (nm) with First } 15 \\
\text { Highest Factor Loadings }\end{array}$} & \multicolumn{3}{|c|}{$\begin{array}{l}\text { Percent Variability } \\
\text { Explained }\end{array}$} & \multirow[t]{2}{*}{$\begin{array}{l}\text { Cumulative } \\
\text { Variability } \\
\text { of three PCs }\end{array}$} \\
\hline \multicolumn{7}{|c|}{ Switchgrass Cultivars } & \\
\hline & $\mathrm{PC} 1$ & PC2 & PC3 & PC1 & PC2 & PC3 & \\
\hline${ }^{1}$ 24-Мay-2011 & $\begin{array}{c}1670 ; 1660 ; 1680 \\
1690 ; 1700\end{array}$ & $\begin{array}{l}780 ; 800 ; 790 \\
770 ; 810\end{array}$ & $\begin{array}{l}670 ; 680 ; 660 \\
690 ; 500\end{array}$ & 58 & 23 & 14 & 95 \\
\hline $\begin{array}{l}\text { Dominating } \\
\text { waveband }\end{array}$ & Mid-IR & NIR & RED & & & & \\
\hline${ }^{1}$ 20-June-2011 & $\begin{array}{c}1730 ; 1710 ; 1720 \\
1700 ; 1740\end{array}$ & $\begin{array}{c}1440 ; 1460 \\
1430 \\
1450 ; 2050\end{array}$ & $\begin{array}{l}520 ; 570 ; 530 \\
540 ; 590\end{array}$ & 74 & 14 & 9 & 97 \\
\hline $\begin{array}{l}\text { Dominating } \\
\text { waveband }\end{array}$ & Mid-IR & Mid-IR & GREEN & & & & \\
\hline 1 25-July-2011 & $\begin{array}{c}1750 ; 1740 ; 1720 \\
1730 ; 1760\end{array}$ & $\begin{array}{c}2020 ; 2030 ; \\
2010 ; 2000 ; \\
2040\end{array}$ & $\begin{array}{l}630 ; 620 ; 610 \\
700 ; 600\end{array}$ & 64 & 20 & 11 & 95 \\
\hline $\begin{array}{l}\text { Dominating } \\
\text { waveband }\end{array}$ & Mid-IR & Mid-IR & RED & & & & \\
\hline 1 24-August-2011 & $\begin{array}{c}1700 ; 1740 ; 1720 \\
1710 ; 1730\end{array}$ & $\begin{array}{c}740 ; 2040 ; \\
2030 ; 2020 ; \\
2050\end{array}$ & $\begin{array}{l}700 ; 600 ; 610 \\
620 ; 590\end{array}$ & 62 & 24 & 10 & 96 \\
\hline $\begin{array}{l}\text { Dominating } \\
\text { waveband }\end{array}$ & Mid-IR & Mid-IR & RED & & & & \\
\hline $\begin{array}{l}{ }^{1} \text { 30-September- } \\
2011\end{array}$ & $\begin{array}{c}1750 ; 1760 ; 1740 \\
1770 ; 1730\end{array}$ & $\begin{array}{l}840 ; 890 ; 800 \\
880 ; 810\end{array}$ & $\begin{array}{l}520 ; 530 ; 510 \\
540 ; 550\end{array}$ & 56 & 27 & 10 & 93 \\
\hline $\begin{array}{c}\text { Dominating } \\
\text { waveband }\end{array}$ & Mid-IR & NIR & GREEN & & & & \\
\hline $\begin{array}{l}\text { Dominating } \\
\text { waveband for }\end{array}$ & Mid-IR & Mid-IR & RED & & & & \\
\hline $\begin{array}{l}\text { Switchgrass } \\
\text { Cultivars }\end{array}$ & & & & & & & \\
\hline Mean (\%) & & & & 63 & 22 & 11 & 95 \\
\hline \multicolumn{8}{|c|}{ Nitrogen Treatments } \\
\hline${ }^{1}$ 17-Juny-2011 & $\begin{array}{c}1770 ; 1660 ; 1670 \\
1760 ; 1650\end{array}$ & $\begin{array}{c}2000 ; 2010 ; \\
1990 ; 1980 ; \\
2020\end{array}$ & $\begin{array}{l}520 ; 510 ; 580 \\
610 ; 600\end{array}$ & 50 & 32 & 15 & 97 \\
\hline $\begin{array}{c}\text { Dominating } \\
\text { waveband }\end{array}$ & Mid-IR & Mid-IR & GREEN & & & & \\
\hline
\end{tabular}


Table 4. Cont.

\begin{tabular}{|c|c|c|c|c|c|c|c|}
\hline \multicolumn{4}{|c|}{$\begin{array}{l}\text { Wavelength Centered (nm) with First } 15 \\
\text { Highest Factor Loadings }\end{array}$} & \multicolumn{3}{|c|}{$\begin{array}{l}\text { Percent Variability } \\
\text { Explained }\end{array}$} & \multirow{2}{*}{$\begin{array}{c}\begin{array}{c}\text { Cumulative } \\
\text { Variability } \\
\text { of three PCs }\end{array} \\
96\end{array}$} \\
\hline${ }^{1}$ 27-July-2011 & $\begin{array}{c}1620 ; 1600 ; 1650 \\
1610 ; 1630\end{array}$ & $\begin{array}{c}780 ; 790 ; 800 \\
770 ; 810\end{array}$ & $\begin{array}{l}500 ; 490 ; 510 \\
480 ; 470\end{array}$ & 54 & 32 & 10 & \\
\hline $\begin{array}{l}\text { Dominating } \\
\text { waveband }\end{array}$ & Mid-IR & NIR & BLUE & & & & \\
\hline${ }^{1}$ 26-August-2011 & $\begin{array}{c}1730 ; 1620 ; 1740 \\
1600 ; 1720\end{array}$ & $\begin{array}{c}950 ; 990 ; 980 ; \\
930 ; 970\end{array}$ & $\begin{array}{c}520 ; 510 ; 640 ; \\
620 ; 630\end{array}$ & 55 & 23 & 17 & 95 \\
\hline $\begin{array}{c}\text { Dominating } \\
\text { waveband for } \\
\mathbf{N} \text { treatment }\end{array}$ & Mid-IR & NIR & GREEN & & & & \\
\hline Mean (\%) & & & & 53 & 29 & 14 & 96 \\
\hline $\begin{array}{c}{ }^{2} \text { Dominating } \\
\text { waveband for all of } \\
\text { the above }\end{array}$ & Mid-IR & NIR/Mid-IR & GREEN & & & & \\
\hline Overall Mean (\%) & & & & 58 & 26 & 13 & 96 \\
\hline
\end{tabular}

Blue (400-520 nm); Green (520-590); Red (600-690 nm); NIR: near infrared (700-1300 nm); Mid-IR:

Middle infrared (1350-2500 nm). ${ }^{1}$ Date of data collection; ${ }^{2}$ Dominant waveband portions in all switchgrass cultivar and $\mathrm{N}$ treatments.

The result of the principal component analysis of the pigment profiles showed that over $98 \%$ of the variability could be explained using the first two principal components. Table 5 summarizes the result of the PCA for the pigment profiles. The PC1 was dominated equally by total chlorophyll and carotenoid concentrations explaining 70 and $72 \%$ of the variability and PC2 by phenolics compounds concentration explaining 29 and $27 \%$ of the variability for switchgrass cultivars and nitrogen treatments respectively. Photosynthetic pigments were better able to discriminate among the cultivars and $\mathrm{N}$ treatments than UV-B absorbing compounds.

Table 5. Shows PCA results with pigments in order of the highest factor loadings (Eigen vectors) and the percent variability explained by each principal for characterizing 12 switchgrass cultivars and five nitrogen treatments.

\begin{tabular}{|c|c|c|c|c|c|}
\hline & \multicolumn{2}{|c|}{$\begin{array}{c}\text { Wavelength Centered (nm) Pigments and } \\
\text { Factor Loadings in Parenthesis } \\
\end{array}$} & \multirow{2}{*}{$\begin{array}{l}\text { Percent Variability } \\
\text { Explained } \\
\mathrm{s}\end{array}$} & \multicolumn{2}{|r|}{$\begin{array}{c}\text { Cumulative Variability } \\
\text { of PCs }\end{array}$} \\
\hline \multicolumn{5}{|c|}{ Switchgrass Cultivars } & \\
\hline & $\mathrm{PC} 1$ & $\mathrm{PC} 2$ & $\mathrm{PC} 1$ & $\mathrm{PC} 2$ & \\
\hline${ }^{1}$ 24-May-2011 & $\begin{array}{c}\text { Tchl }(0.68) \text { Cart } \\
(0.68) \text { Phen }(-0.26)\end{array}$ & $\begin{array}{l}\text { Phen }(0.97) \text { Tchl } \\
(0.19) \text { Cart }(0.17)\end{array}$ & 68 & 31 & 99 \\
\hline $\begin{array}{l}\text { Dominating } \\
\text { Pigments }\end{array}$ & Tchl \& Cart & Phen & & & \\
\hline 1 20-June-2011 & $\begin{array}{c}\text { Tchl }(0.68) \text { Cart } \\
(0.67) \text { Phen }(-0.31)\end{array}$ & $\begin{array}{l}\text { Phen }(0.95) \text { Cart } \\
(0.26) \text { Tchl }(0.17)\end{array}$ & 70 & 30 & 100 \\
\hline $\begin{array}{l}\text { Dominating } \\
\text { Pigments }\end{array}$ & Tchl \& Cart & Phen & & & \\
\hline
\end{tabular}


Table 5. Cont.

\begin{tabular}{|c|c|c|c|c|c|}
\hline & \multicolumn{2}{|c|}{$\begin{array}{l}\text { Wavelength Centered (nm) Pigments } \\
\text { and Factor Loadings in Parenthesis }\end{array}$} & \multicolumn{2}{|l|}{$\begin{array}{c}\text { Percent Variability } \\
\text { Explained } \\
\end{array}$} & $\begin{array}{c}\text { Cumulative } \\
\text { Variability of PCs } \\
\end{array}$ \\
\hline${ }^{1}$ 25-July-2011 & $\begin{array}{l}\text { Tchl (0.68) Cart } \\
\begin{array}{c}(0.68) \text { Phen } \\
(-0.28)\end{array}\end{array}$ & $\begin{array}{l}\text { Phen (0.96) Cart } \\
(0.22) \text { Tchl }(0.18)\end{array}$ & 68 & 30 & 98 \\
\hline Dominating Pigments & Tchl \&Cart & Phen & & & \\
\hline${ }^{1}$ 24-August-2011 & $\begin{array}{l}\text { Tchl (0.65) Cart } \\
\begin{array}{c}(0.65) \text { Phen } \\
(-0.40)\end{array}\end{array}$ & $\begin{array}{l}\text { Phen }(0.92) \text { Tchl } \\
(0.30) \text { Cart }(0.26)\end{array}$ & 74 & 26 & 100 \\
\hline Dominating Pigments & Tchl \& Cart & Phen & & & \\
\hline${ }^{1}$ 30-September-2011 & $\begin{array}{l}\text { Tchl (0.66) Cart } \\
\begin{array}{c}(0.66) \text { Phen } \\
(-0.36)\end{array}\end{array}$ & $\begin{array}{l}\text { Phen }(0.93) \text { Tchl } \\
(0.27) \text { Cart }(0.24)\end{array}$ & 72 & 28 & 100 \\
\hline Dominating Pigments & Tchl \& Cart & Phen & & & \\
\hline $\begin{array}{l}\text { Dominating Pigments for } \\
\text { Switchgrass Cultivars }\end{array}$ & Tchl \& Cart & Phen & & & \\
\hline Mean (\%) & & & 70 & 29 & 99 \\
\hline \multicolumn{6}{|c|}{ Nitrogen Treatments } \\
\hline${ }^{1}$ 17-June-2011 & $\begin{array}{l}\text { Tchl }(0.64) \text { Cart } \\
(0.63) \text { Phen } \\
(-0.43)\end{array}$ & $\begin{array}{l}\text { Phen (0.90) Cart } \\
(0.33) \text { Tchl }(0.26)\end{array}$ & 76 & 24 & 100 \\
\hline Dominating Pigments & Tchl \& Cart & Phen & & & \\
\hline${ }^{1}$ 27-July-2011 & $\begin{array}{l}\text { Tchl (0.66) Cart } \\
(0.65) \text { Phen }(0.37)\end{array}$ & $\begin{array}{c}\text { Phen (0.90) Cart } \\
(-0.30) \text { Tchl } \\
(-0.24)\end{array}$ & 73 & 27 & 100 \\
\hline Dominating Pigments & Tchl \& Cart & Phen & & & \\
\hline${ }^{1}$ 26-August-2011 & $\begin{array}{l}\text { Tchl }(0.70) \text { Cart } \\
(0.70) \text { Phen }(0.08)\end{array}$ & $\begin{array}{c}\text { Phen (1.0) Tchl } \\
(-0.06) \text { Cart }(-0.06)\end{array}$ & 66 & 33 & 99 \\
\hline $\begin{array}{c}\text { Dominating Pigments for } \\
\mathrm{N} \text { treatment }\end{array}$ & Tchl \& Cart & Phen & & & \\
\hline Mean (\%) & & & 72 & 27 & 100 \\
\hline $\begin{array}{l}{ }^{2} \text { Dominating Pigments } \\
\text { for all above }\end{array}$ & Tchl \& Cart & Phen & & & \\
\hline Overall Mean (\%) & & & 71 & 28 & 99 \\
\hline
\end{tabular}

Tchl: total chlorophyll; Cart: carotenoids; Phen: phenolics. ${ }^{1}$ Date of data collection; ${ }^{2}$ Dominant pigments in all switchgrass cultivar and $\mathrm{N}$ treatments.

\subsection{Discriminant Analysis}

Discriminant analysis of the first five PC of the spectral data resulted in an overall classification accuracy of 14, 14, 3, 3 and 81\% with cross-validation for data collected in the months of May, June, July, August and September respectively, for switchgrass cultivars. In contrast, DA of the pigment data resulted in an overall classification accuracy of $6,0,23,17$ and $11 \%$ with cross-validation for the five collection dates in chronological order. The greatest difficulty was in classifying Kanlow (44\%) which was misclassified as either Southlow or Cimarron. Cultivars Sunburst, Alamo, Southlow and Nebraska 
28 were classified with $67 \%$ accuracy into the correct group. Carthage, Shawnee, Cave-In-Rock, Forestburg, Blackwell and Shelter were classified with 100\% accuracy into the correct group. Contrary to the switchgrass cultivars, classification of the $\mathrm{N}$ treatment based on pigment data was $20 \%$ greater than spectral data. Classification of nitrogen treatment based on spectral data ranges from 7 to $27 \%$ at the different sampling dates. The most accurate classification was achieved in the August sampling. While, classification of $\mathrm{N}$ treatments based on pigment data ranged from 7 to $47 \%$ for the different sampling dates. Likewise, the most accurate classification was achieved in the August sampling. These results indicate that the accuracy of discriminating among the twelve switchgrass cultivars and five $\mathrm{N}$ treatments was highest towards the end of the growing season. It must be pointed out, that it was clear from the charts in Figure 2 and 3 that there was little difference among $\mathrm{N}$ treatments and clear difference in the month of September for the cultivars. Therefore, the statistical analysis substantiates what can be deduced from those figures. The inability to discriminate among the five $\mathrm{N}$ treatments could be attributed to late application of the $\mathrm{N}$ in early June at the time when switchgrass cultivars were over $1.2 \mathrm{~m}$ tall compounded with the severe drought condition experienced during the 2011 growing season in Oklahoma. Response of switchgrass grown for biomass to $\mathrm{N}$ fertilization has been reported in studies across the USA [34-36]. Thomason et al. [35] found limited response to N with $\mathrm{N}$ rate up to $448 \mathrm{~kg} \cdot \mathrm{N} \cdot \mathrm{ha}^{-1}$ in Oklahoma and Vogel et al. [36] and Lemus et al. [34]reported switchgrass response to $\mathrm{N}$ fertilization to be dependent on location.

\subsection{Selection of the Best Vegetation Indices}

Stepwise discriminant analysis was carried out to identify the best indices at each sampling interval, from the list of indices in Table 3, for discrimination. The results of the SDA for the twelve switchgrass cultivars showed the optimal Wilk's lambda values were achieved with different indices at each sampling intervals. The values of Wilk's lambda were indicative of discriminatory power of the vegetation indices, with the lesser the Wilk's lambda the greater the degree of differentiation between the cultivars and nitrogen treatments. The optimal Wilk's lambda values were achieved using two (0.184), one (0.564) and thirteen (0.000) vegetation indices for sampling intervals in June, July and September, respectively, in differentiating the twelve switchgrass cultivars and with one $(0.443)$, four (0.024) and two (0.12) vegetation indices for sampling interval June, July and August, respectively, for the five $\mathrm{N}$ treatments. The Wilk's lambda was lowest for the months of September and July for switchgrass cultivars and $\mathrm{N}$ treatments, again indicating that sampling interval was critical in discriminating among the twelve switchgrass cultivars and $\mathrm{N}$ treatments. The Wilk's lambda for the model with only PSRI (0.050) in the month of September was relatively smaller in comparison to the overall Wilk's lambda for the models at the other sampling intervals. Therefore, PSRI was found to be the best indices and the month of September the best time for data collection for discriminating among the twelve cultivars. For nitrogen, the lowest Wilk's lambda was achieved for the July sampling with TCARI, MCARI, SIPI, EVI, in the model. The Wilk's lambda with only the TCARI $(0.250)$ in the model for the month of August was smaller in comparison to Wilk's lambda for June with TVI. These results indicate that TCARI was the best index and the month of July was the best time for data collection for discriminating among the five $\mathrm{N}$ treatments. 


\section{Discussion}

Optimal wavebands are those bands that have the least correlation among them, high information content and are able to discriminate the target. Currently there is no best approach available to determine the optimal number of bands required to discriminate vegetation characteristics [10]. Researchers in the past have used various approaches from incorporating reflectance from individual narrowbands, various indices derivatives of reflectance spectra, or combinations of these. Using discriminant analysis of reflectance data resulted with correctly grouping the twelve cultivars into their respective grouping with an accuracy of $80 \%$ using cross-validation and $100 \%$ using re-substitution methods for the September sampling. Pigment data was unable to discriminate among the cultivars. However, in discriminating among $\mathrm{N}$ treatments pigment data was found to be better than the spectral data. Likewise, Johnson et al. [13] found greater accuracy (95-100\%) in classifying sugarcane varieties with leaf spectral reflectance data in comparison to $76-81 \%$ accuracy with plant pigment data. The ability to use spectral reflectance data obtained from a spectroradiometer to discriminate or identify plant varieties or cultivars is based on the leaf spectral characteristics that are related to the leaf pigment profile and structure. The leaf spectral characteristics of plants is affected by many factors such as plant species, leaf maturity, microclimate position of the leaf on the plant [37], environmental condition in which plant is grown and time of data collection. The amount of light reflected, absorbed or transmitted in the visible $(400-700 \mathrm{~nm})$, near infrared $(700-1,350 \mathrm{~nm})$ and middle-infrared $(1,350-2,500 \mathrm{~nm})$ is primarily controlled by the leaf pigment profile, internal leaf structure, and in vivo water content respectively [8]. The PCA found middle infrared to be the dominant waveband for PC1 explaining $63 \%$ of the variability, NIR wavebands in May and September, and middle infrared wavebands in June, July and August to be the dominant wavebands for PC2 explaining 22\% variability and red wavebands in May, July and August and green wavebands in June and September for PC3 explaining 11\% of the variability. Thenkabail et al. [10] also found middle infrared wavebands to be the dominant waveband for PC 1 and accounting for a similar $62 \%$ of the variability. The middle infrared region of the spectrum dominated the PC1 with a $63 \%$ frequency of occurrence suggests that in vivo water content within leaf was the dominant characteristic for discriminating among the cultivars.

The information generated from vegetation indices depends upon the phenological stage and plant parameter to which the index is most closely related [15]. This study identified SDA models with different vegetation indices for discriminating among the cultivars at different sampling intervals, Chlorophyll red edge index and EVI in June, red edge ratio in July and PSRI in September, which is indicative of an index influenced by the phenological or plant parameter to which it is most closely related. The PSRI an index proposed to be sensitive to the senescence phase of plant development had the lowest Wilk's lambda value in differentiating among the cultivars. This index was most sensitive to the senescence phase in being able to discriminate among the cultivars at leaf level. The PSRI defined as $\left(\operatorname{Red}_{660}-\right.$ Green $\left._{510}\right) / \mathrm{NIR}_{760}$, takes advantage of the reflectance relationships in red, green and near infrared regions of the spectrum [15]. The relatively large Wilk's lambda value also suggests that the degree of separation was poor in the months of June and July. The low accuracy in classifying the cultivars during these months confirms this. Furthermore, chlorophyll/pigment related indices that most closely match to the leaf chlorophyll content were most dominant in discriminating among the $\mathrm{N}$ treatments. Nitrogen concentration in green plants is related to chlorophyll content [38]. Studies have 
shown that leaf chlorophyll content can indicate $\mathrm{N}$ stress in corn [39], rice [40,41], and sorghum [42]. The indices identified that discriminated among the $\mathrm{N}$ treatments were dominated by chlorophyll/pigment related computed indices (SIPI, MCARI and TCARI), again showing relation to the parameter the index is most closely related. TCARI an index that is sensitive to changes in chlorophyll concentrations takes advantage of the reflectance relationships in the red, red edge and green regions of the spectrum occurred in both July and August model for discrimination. The dominant plant pigments were the chlorophyll and carotenoids explaining over $70 \%$ of the variability in PC1 (Table 4). In general, chlorophyll reflectance and absorption is associated with a green peak $(\sim 550 \mathrm{~nm})$ followed by a decrease in red reflectance $(\sim 650-690 \mathrm{~nm})$. High spectral resolution measurements of chlorophyll in the red edge region (700-795 nm) was found to detect trace quantities of green vegetation [43]. A leaf simulated reflectance analysis using PROSPECT model was conducted by Haboudane et al. [38]. They reported a negative correlation between TCARI and chlorophyll concentration over a range of $\left(10-70 \mu \mathrm{g} / \mathrm{cm}^{2}\right)$, and a positive one at concentration below $10 \mu \mathrm{g} / \mathrm{cm}^{2}$. This indicates that TCARI is highly sensitive to low concentration of chlorophyll.

\section{Conclusions}

Hyperspectral narrowbands leaf reflectance was able to better discriminate among switchgrass cultivars with $80 \%$ accuracy in the month of September in comparison to pigment data. Separation of the nitrogen treatments was more difficult from leaf reflectance data (27\% correct classification) than with leaf pigment data (47\% correct classification) for the month of August. Hyperspectral narrowbands indices that take leaf structure into account were found to be most dominant in discriminating the cultivars, while chlorophyll pigment based indices were most dominant for the $\mathrm{N}$ treatments. The result showed greater success in separating the cultivars using leaf spectral data close to the end of the growing season or harvesting. This finding could be beneficial in development of prediction models for estimating biomass yield for the different cultivars. However, the real benefit in discriminating among cultivars is the ability to discriminate at canopy level in the field. The use of non-destructive techniques to discriminate among cultivars and $\mathrm{N}$ treatments at field level could provide an opportunity to evaluate cultivar performance with more detailed genomic or production yield studies and $\mathrm{N}$ management in real time. Additional research work is required to determine the ability to discriminate among switchgrass cultivars at canopy level.

\section{Acknowledgements}

This study was funded by USDA-NIFA through the Biomass Research and Development Initiative (BRDI), a joint effort between the US Department of Agriculture (USDA) and the US Department of Energy (DOE). This manuscript is a contribution of the Oklahoma Agricultural Experiment Station, Oklahoma State University, Stillwater, OK, USA.

\section{References}

1. Parrish, D.J.; Fike, J.H. The biology and agronomy of switchgrass for biofuels. Crit. Rev. Plant Sci. 2005, 24, 423-459. 
2. Sanderson, M.A.; Reed, R.L.; McLaughlin, S.B.; Wullschleger, S.D.; Conger, B.V.; Parrish, D.J.; Wolf, D.D.; Taliaferro, C.; Hopkins, A.A.; Ocumpaugh, W.R.; et al. Switchgrass as a sustainable bioenergy crop. Bioresour. Technol. 1996, 56, 83-93.

3. Wullschleger, S.D.; Davis, E.B.; Borsuk, M.E.; Gunderson, C.A.; Lynd, L.R. Biomass production in Switchgrass across the United States: Database description and determinants of yield. Agron. J. 2010, 102, 1158-1168.

4. Fike, J.H.; Parrish, D.J.; Wolf, D.D.; Balasko, J.A.; Green, J.T.; Rasnake, M.; Reynolds, J.H. Long-term yield potential of switchgrass-for-biofuel systems. Biomass Bioenerg. 2006, 30, 198-206.

5. Muir, J.P.; Sanderson, M.A.; Ocumpaugh, W.R.; Jones, R.M.; Reed, R.L. Biomass production of 'Alamo' switchgrass in response to nitrogen, phosphorus, and row spacing. Agron. J. 2001, 93, 896-901.

6. Cassida, K.A.; Muir, J.P.; Hussey, M.A.; Read, J.C.; Venuto, B.C.; Ocumpaugh, W.R. Biomass yield and stand characteristics of switchgrass in south central US environments. Crop Sci. 2005, 45, 673-681.

7. Parrish, D.J.; Fike, J.H.; Bransby, D.I.; Samson, R. Establishing and managing switchgrass as an energy crop. Forage Grazinglands 2008, doi:10.1094/FG-2008-0220-01-RV.

8. Lusch, D.P. Introduction to Environmental Remote Sensing; Center for Remote Sensing and GIS Michigan State University: East Lansing, MI, USA 1999.

9. Barnes, E.M.; Moran, M.S.; Pinter, P.J.,Jr.; Clarke, T.R. Multispectral Remote Sensing and Site-Specific Agriculture: Examples of Current Technology and Future Possibilities. In Proceedings of the International Conference on Precision Agriculture, Minneapolis, MN, USA, 23 June 1996; pp. 843-854.

10. Thenkabail, P.S.; Enclona, E.A.; Ashton, M.S.; van der Meer, B. Accuracy assessments of hyperspectral waveband performance for vegetation analysis applications. Remote Sens. Environ. 2004, 91, 354-376.

11. McGwire, K.; Minor, T.; Fenstermaker, L. Hyperspectral mixture modeling for quantifying sparse vegetation cover in arid environments. Remote Sens. Environ. 2000, 72, 360-374.

12. Penuelas, J.; Gamon, J.A.; Fredeen, A.L.; Merino, J.; Field, C.B. Reflectance indices associated with physiological changes in nitrogen- and water-limited sunflower leaves. Remote Sens. Environ. 1994, 48, 135-146.

13. Johnson, R.M.; Viator, R.P.; Veremis, J.C.; Richard, P.E.; Zimba, P.V. Discrimination of sugarcane varieties with pigment profiles and high resolution, hyperspectral leaf reflectance data. J. Am. Soc. Sugar Cane Technol. 2008, 28, 63-75.

14. Ray, S.S.; Singh, J.P.; Panigrahy, S. Use of hyperspectral remote sensing data for crop stress detection: Ground-based studies. Int. Arch. Photogramm. Remote Sens. Spat. Inf. Sci. 2010, 38, 562-567.

15. Hatfield, J.L.; Prueger, J.H. Value of using different vegetative indices to quantify agricultural crop characteristics at different growth stages under varying management practices. Remote Sens. 2010, 2, 562-578.

16. Lichtenthaler, H.K. Chlorophylls and carotenoids-pigments of photosynthetic biomembranes. Methods Enzymol. 1987, 148, 350-382. 
17. Kakani, V.G.; Reddy, K.R.; Zhao, D.; Koti, S.; Gao, W. Interactive effects of ultraviolet-B radiation and temperature on cotton physiology, growth, development and hyperspectral reflectance. Photochem. Photobiol. 2004, 79, 416-427.

18. SAS. SAS User's Guide; SAS Institute Inc.: Cary, NC, USA, 2009.

19. Mahalanobis, P.C. On the generalized distance in statistics. Proc. Nat. Inst. Sci. India 1936, 2, 49-55.

20. Birth, G.S.; Mcvey, G.R. Measuring color of growing turf with a reflectance spectrophotometer. Agron. J. 1968, 60, 640-643.

21. Rouse, J.W.; Hass, R.H.; Schell, J.A.; Deering, D.W. Monitoring Vegetation System in Great Plains with ERTS. In Proceedings of the Third Earth Resources Technology Satellite-1 Symposium, Greenbelt, MD, USA, 10-14 December 1973; pp. 48-62.

22. Gitelson, A.A.; Gritz,Y.; Merzlyak, M.N. Relationships between leaf chlorophyll content and spectral reflectance and algorithms for non-destructive chlorophyll assessment in higher plant leaves. J. Plant Physiol. 2003, 160, 271-282.

23. Roujean, J.L.; Breon, F.M. Estimating par absorbed by vegetation from bidirectional reflectance measurements. Remote Sens. Environ. 1995, 51, 375-384.

24. Huete, A.; Didan, K.; Miura, T.; Rodriguez, E.P.; Gao, X.; Ferreira, L.G. Overview of the radiometric and biophysical performance of the MODIS vegetation indices. Remote Sens. Environ. 2002, 83, 195-213.

25. Merzlyak, M.N.; Gitelson, A.A.; Chivkunova, O.B.; Rakitin, V.Y. Non-destructive optical detection of pigment changes during leaf senescence and fruit ripening. Physiol. Plant. 1999, 106, 135-141.

26. Gitelson, A.A.; Vina, A.; Ciganda, V.; Rundquist, D.C.; Arkebauer, T.J. Remote estimation of canopy chlorophyll content in crops. Geophys. Res. Lett. 2005, doi:10.1029/2005GL022688.

27. Daughtry, C.S.T.; Walthall, C.L.; Kim, M.S.; de Colstoun, E.B.; McMurtrey, J.E. Estimating corn leaf chlorophyll concentration from leaf and canopy reflectance. Remote Sens. Environ. 2000. 74, 229-239.

28. Haboudane, D.; Miller, J.R.; Pattey, E.; Zarco-Tejada, P.J.; Strachan, I.B. Hyperspectral vegetation indices and novel algorithms for predicting green LAI of crop canopies: Modeling and validation in the context of precision agriculture. Remote Sens. Environ. 2004, 90, 337-352.

29. Broge, N.H.; LeBlanc, E. Comparing predictive power and stability of broad-band and hyperspectral vegetation indices for estimation of green leaf area index and canopy chlorophyll density. Remote Sens. Environ. 2000, 76, 156-172.

30. Penuelas, J.; Filella, I.; Lloret, P.; Munoz, F.; Vilajeliu, M. Reflectance assessment of mite effects on apple-trees. Int. J. Remote Sens. 1995, 16, 2727-2733.

31. Gitelson, A.A.; Merzlyak, M.N. Remote estimation of chlorophyll content in higher plant leaves. Int. J. Remote Sens. 1997, 18, 2691-2697.

32. Vogelmann, J.E.; Rock, B.N.; Moss, D.M. Red edge spectral measurements from sugar maple leaves. Int. J. Remote Sens. 1993, 14, 1563-1575.

33. Zarco-Tejada, P.J.; Miller, J.R.; Noland, T.L.; Mohammed, G.H.; Sampson, P.H. Scaling-up and model inversion methods with narrowband optical indices for chlorophyll content estimation in closed forest canopies with hyperspectral data. IEEE Trans. Geosci. Remote Sens. 2001, 39, 1491-1507. 
34. Lemus, R.; Parrish, D.J.; Abaye, O. Nitrogen-use dynamics in switchgrass grown for biomass. Bioenergy Res. 2008, 1, 153-162.

35. Thomason, W.E.; Raun, W.R.; Johnson, G.V.; Taliaferro, C.M.; Freeman, K.W.; Wynn, K.J.; Mullen, R.W. Switchgrass response to harvest frequency and time and rate of applied nitrogen. J. Plant Nutr. 2004, 27, 1199-1226.

36. Vogel, K.P.; Brejda, J.J.; Walters, D.T.; Buxton, D.R. Switchgrass biomass production in the Midwest USA: Harvest and nitrogen management. Agron. J. 2002, 94, 413-420.

37. Jacquemoud, S.; Ustin, S.L. Leaf Optical Properties: A State of the Art. In Proceedings of the 8th International Symposium on Physical Measurements and Signatures in Remote Sensing, Aussois, France, 8-12 January 2001; pp. 223-232.

38. Haboudane, D.; Miller, J.R.; Tremblay, N.; Zarco-Tejada, P.J.; Dextraze, L. Integrated narrow-band vegetation indices for prediction of crop chlorophyll content for application to precision agriculture. Remote Sens. Environ. 2002, 81, 416-426.

39. Scharf, P.C.; Schmidt, J.P.; Kitchen, N.R.; Sudduth, K.A. Remote sensing for nitrogen management. J. Soil Water Conserv. 2002, 57, 518-523.

40. Cabangon, R.J.; Castillo, E.G.; Tuong, T.P. Chlorophyll meter-based nitrogen management of rice grown under alternate wetting and drying irrigation. Field Crops Res. 2011, 121, 136-146.

41. Lin, F.F.; Qiu, L.F.; Deng, J.S.; Shi, Y.Y.; Chen, L.S.; Wang, K. Investigation of SPAD meter-based indices for estimating rice nitrogen status. Comput. Electron. Agric. 2010, 71, S60-S65.

42. Van Oosterom, E.J.; Chapman, S.C.; Borrell, A.K.; Broad, I.J.; Hammer, G.L. Functional dynamics of the nitrogen balance of sorghum. II. Grain filling period. Field Crops Res. 2010, 115, 29-38.

43. Elvidge, C.D.; Chen, Z.K.; Groeneveld, D.P. Detection of trace quantities of green vegetation in 1990 AVIRIS data. Remote Sens. Environ. 1993, 44, 271-279.

(C) 2012 by the authors; licensee MDPI, Basel, Switzerland. This article is an open access article distributed under the terms and conditions of the Creative Commons Attribution license (http://creativecommons.org/licenses/by/3.0/). 